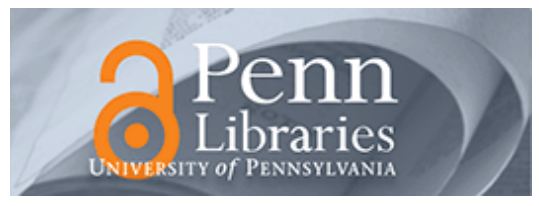

Studies in Visual Communication

Volume 2

Issue 2 Fall 1975

Article 5

1975

\title{
Cinéma Naïveté: A Study of Home Moviemaking as Visual Communication
}

Richard Chalfen

\section{Recommended Citation}

Chalfen, R. (1975). Cinéma Naïveté: A Study of Home Moviemaking as Visual Communication. 2 (2), 87-103. Retrieved from https://repository.upenn.edu/svc/vol2/iss2/5

This paper is posted at ScholarlyCommons. https://repository.upenn.edu/svc/vol2/iss2/5

For more information, please contact repository@pobox.upenn.edu. 
Cinéma Naïveté: A Study of Home Moviemaking as Visual Communication

This contents is available in Studies in Visual Communication: https://repository.upenn.edu/svc/vol2/iss2/5 


\section{CINÉMA NAÏVETÉ:}

\section{A STUDY OF HOME MOVIEMAKING AS VISUAL COMMUNICATION ${ }^{1}$}

\section{RICHARD CHALFEN}

In comparison with other types of films, home movies are stereotypically thought of as films of everyday life, of commonplace family activities, of life around the house, and the like. At face value, such films seem to be extremely rich in ethnographic data, and as such, should be valued by social scientists as native views of initimate realities. ${ }^{2}$ One objective of this paper is to examine this proposition as data about the problematic relationship between the symbolic reality of the home movie medium, the stated cultural and technical prescriptions about its use, and the reality of everyday life. A related objective is to better understand the notion of symbolic manipulation as it applies to one genre of film communication-namely, home movies.

The paper is divided into four parts. The study of film communication is discussed first. Second, home movies are examined in general terms with some reference to previous and ongoing attention to the medium. Third, the structure of home movies and the process of home moviemaking are analyzed in terms of communication "events" and communication "components." The fourth section consists of a functional analysis of the home movie medium as a cultural enterprise.

\section{FILM COMMUNICATION AND HOME MOVIES}

Film communication is being studied here as a process of human social behavior that manipulates a recording on film for the purpose of articulating some meaningful content or message through the pattern we impose and the way we structure the content as well as the actual pieces of celluloid. A film (or group of films) is understood as a symbolic form that is produced and viewed as part of a process of human

Richard Chalfen is an Assistant Professor of Anthropology at Temple University in Philadelphia, specializing in the areas of culture and communication, visual communication and vidistics. His research interests include teenage filmmaking, the home mode of visual communication and, most recently, the anthropology of mass media. His published papers include "Reaction to Socio-Documentary Filmmaking Research at a Mental Health Clinic" (with Jay Haley), "How Groups in Our Society Act When Taught to Use Movie Cameras" (with Sol Worth), and "Introduction to the Home Mode of Visual Communication."

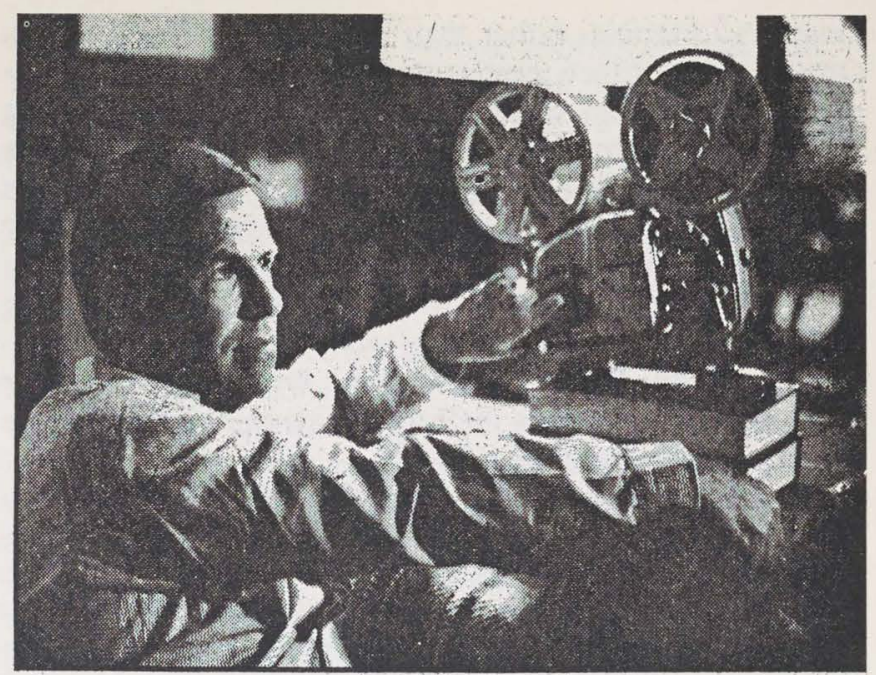

Those home movies on TV-more bombshells to come?

Figure 1

behavior organized within social and cultural contexts. Behaviors surrounding filmmaking are understood as promoted, limited, or restricted primarily by social norms rather than as limitations primarily imposed by psychological or technical variables.

Film communication can thus be studied as the creation, manipulation, and interpretation of symbolic events that occur in, and as, a series of social "performances." Rather than studying filmmaking as an idealized cognitive activity, film communication can be studied ethnographically and comparatively as it actually occurs.

Elsewhere (Chalfen 1974), based on the work of Worth (1966, 1970), Worth and Adair (1972), and Hymes (1962, 1964, 1972), ${ }^{3}$ I have outlined a series of parallels between the ethnography of speaking and an ethnography of film communication. I suggested that any process of film communication can be broken down into four kinds of "events," namely, (1) planning events, (2) filming events (which necessarily includes the two subcategories of "oncamera" events and "behind-camera" events), (3) editing events, and (4) exhibition events. In turn, each of these events can be described as structured by a series of "components," namely, (1) participants, (2) topics, (3) settings, (4) message form, and (5) code. Each of these conceptual units will be described further in the following pages. When each component is referenced with each event, a pattern of activity and behavior emerges that is characteristic of a particular film genre. It is my argument that any film genre can be defined by extracting the relevant event-component relationships from this framework.

This study examines one particular genre and the relationship of one message form, the "home movie," to the other components mentioned above as they systematically operate within a sequence of film communication events.

Home movies are one example of a much larger collection of symbolic behavior that I have called the home mode of visual communication (Chalfen 1975b). This mode of photographic representation is characterized by the non-professional use of communications technology for private "doc- 
umentary" purposes rather than for public or "artistic" use. Other visual artifacts representative of the home mode include family album snapshots, wallet photographs, wedding albums, and photographs displayed on household walls, on television sets, bureaus, and the like. For purposes of this report, primary attention is given to home movies, with only parenthetical examples from other home mode products.

The history of home movies probably begins with the invention of the motion picture camera during the late nineteenth century. Perhaps the Lumiere brothers' Feeding the Baby, filmed in 1895, is the earliest example of home movie content that has been preserved. ${ }^{5}$

The first commercialization of the home movie dates to January of 1923 when the Eastman Kodak Company announced "a new invention enabling motion pictures to be taken by any amateur without difficulties." This introduction of a reversal-processed $16 \mathrm{~mm}$ film was followed in June by the first Cine-Kodak movie outfit, "the first practical camera and projection package for amateur home movies (and) ushered in the era of home movies." According to one account:

They were oversize box cameras that used $16 \mathrm{~mm}$ film, less than half the width of professional motion picture film. It was assumed that most personal-movie pioneers would use their cameras to make real motion pictures, shot from scripts and off the tops of tripods in imitation of Hollywood productions [Knight 1965:v].

However, it was not until 1932 that Kodak introduced the now familiar $8 \mathrm{~mm}$ filmmaking equipment, and by 1936 , $8 \mathrm{~mm}$ color film began replacing the black-and-white stocks. The popular Super-8 equipment, with drop-in cartridges for both cameras and projectors, was introduced as recently as 1969. Sound home movie equipment is the latest innovation, but as of this date, sound movies have not been very popular. ${ }^{6}$

Readers should understand that the home mode process of visual communication and its associated imagery are not determined by type of motion picture equipment. In this sense, home mode imagery can be produced by Bolexes, Auriflexes, and Eclair cameras, as well as the less expensive $8 \mathrm{~mm}$ and Super-8mm equipment. ${ }^{7}$

While the technical aspects of movies reveal some characteristics of the home moviemaker, they tell us little about the social activity that surrounds the use of such technology. We should not be thinking only in terms of what filmmaking equipment is used, but rather how, when, where, and for what purposes it is used, and secondly, of the characteristic social organization that surrounds such activity. I will frequently stress that the communicative importance of home movies is more controlled and structured by social prescriptions and limitations rather than by technical ones.

Another contextual dimension that deserves attention involves home movies as a special kind of visual communication that falls somewhere between forms of interpersonal and mass communication. A form of private and personal communication is produced with technology that is usually associated with forms of mass communication. When Wright describes the process of mass communication, he says:

Although modern technology (television, motion pictures, newspapers, etc.) is essential to the process, its presence does not always signify mass communication... [To] take a more mundane
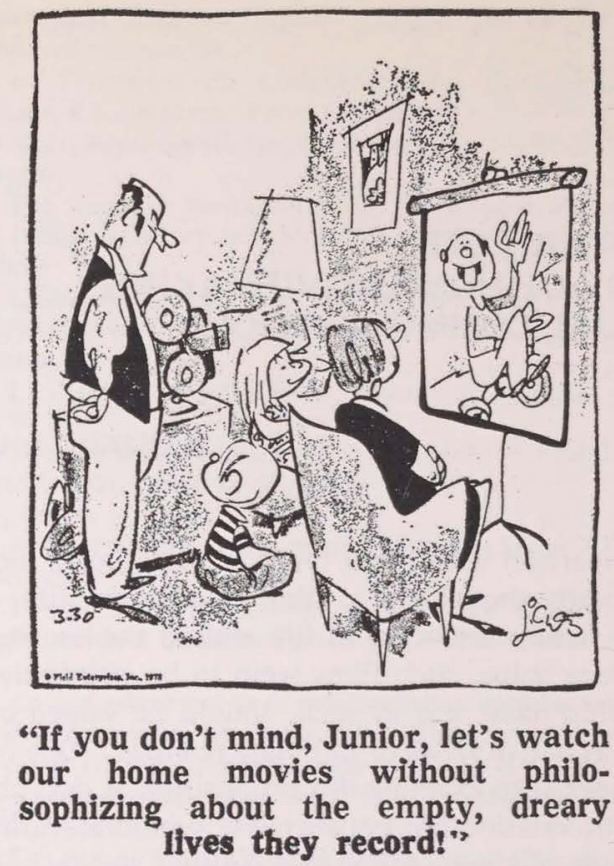

Figure 2

example, a Hollywood motion picture is mass communication; a home movie of vacation scenes is not [Wright 1974:5].

Thus we are not talking about filmmaking as a form of mass communication. Complex formal organization, the need for large capital resources, the need for large audiences of heterogeneous composition, and an impersonal relationship between communicator and audience, are clearly absent from this kind of visual communication.

An example of using movies in an interpersonal context was suggested by the filmmaker Zavattini and has been recorded in an article by John Grierson.

Zavattini once made a funny speech in which he thought it would be wonderful if all the villages in Italy were armed with cameras so that they could make films by themselves and write film letters to each other... [Sussex 1972:30].

Admittedly, this idea was offered as a joke, and I am not suggesting that home movies are now made as "film letters." However, it should be understood that the home mode of visual communication borrows characteristics of other modes and could possibly become popular as a form of film letter just as "tape letters" are now a major form of tape use.

\section{PREVIOUS AND ONGOING ATTENTION TO HOME MOVIEMAKING}

The majority of published material on home movies appears in the form of "How To Do It" manuals and short magazine articles on "How to Improve Your Movies." All of these offer a set of prescriptive guidelines on how to do it "right" and how to avoid "mistakes." This literature contains 
an interesting and quite complete paradigm of idealized behavior which can be compared to the actual home moviemaking behavior that does occur. (A selection of these manuals and articles has been included in the second and third References Cited sections.)

In the literature that deals with the study of film (text books, journal articles, film criticism, etc.), home moviemaking is virtually never mentioned. For most serious minded filmmakers, home movies represent the thing not to do. For the film scholar, it appears that home movies have been too trivial a topic to merit serious attention. ${ }^{8}$

One source of discussion about "home movies" comes from the writing and filmmaking of Jonas Mekas (1972) and Stan Brakhage (1971). However, their use of the term "home movie" is considerably different from the material and process of visual communication being examined in this paper. For instance, Mekas, a filmmaker, film distributor, and film critic for the Village Voice, says:

\begin{abstract}
The avant-garde film-maker, the home moviemaker is here ... presenting to you, he is surrounding you with insights, sensibilities, and forms which will transform you into a better human being. Our home movies are manifestoes of the politics of truth and beauty, beauty and truth. Our films will help to sustain man, spiritually, like bread does, like rain does, like rivers, like mountains, like sun. Come come, you people, and look at us; we mean no harm. So spake [sic] little home movies [1972:352].
\end{abstract}

But I could tell you that some of the most beautiful movie poetry will be revealed, someday, in the $8 \mathrm{~mm}$ home-movie footage... [1972:131].

Films made by members of the New American Cinema such as Jonas Mekas, Stan Brakhage, Ken Jacobs, Shirley Clarke, Gregory Markopoulas, Jack Smith, and, in his early films, Andy Warhol and his imitators, are "home movies" only in the sense of sometimes being filmed "at home" with simple and comparatively inexpensive filmmaking technology.

Another example is provided by Frederick Becker's use of raw home movie footage. Becker's feature length film Heroes is an edited compilation of 25 years of movies made by three families (Van Gelder 1974). ${ }^{9}$ Fabricated home movies and scenes of home moviemaking occasionally appear in feature films. Most notable are the home movie sequences in Up the Sandbox (1972) directed by Irwin Kershner. ${ }^{10}$ In other instances, entire films are being shot and edited in what we sense as a home movie style. ${ }^{11}$ In addition, home movies are seen as a separate and distinct view of a social event in Six Filmmakers in Search of a Wedding.

Another use of the home movie mode occurs in a new genre of avant garde or "art" films of a biographical-confessional nature. A perhaps unusual example is the film titled Film Portrait (1971) by Jerome Hill. This film not only uses examples of his own early films made in the 1920s, but also includes home movies commissioned by his father and photographed by Billy Bitzer, the cameraman for The Great Train Robbery (1903) and other early American films. In that period before Eastman Kodak provided movie cameras for everyone, a railroad tycoon hired a professional cameraman to photograph the same kinds of filmic subject matter that I have seen and studied in the livingrooms of my subjects.

A recent development is the archival collection of "authentic" home movies made by celebrated personalities.
Occasionally, some of this footage appears on television. ${ }^{12}$ The public exhibition of home movies may occur in other contexts. For instance, on October 19, 1973, the Center for Religion and the Arts in New York sponsored a session titled "Home Movies: Great American Folk Art."13 And most recently, the Family Folklore Center showed a selection of home movies and family albums during the Festival of American Folklife in Washington. ${ }^{14}$

In the social science literature, I find no sustained interest in home moviemaking. Reference to either the making of these movies or the movies per se is parenthetical at best. For instance, observations by David Sudnow (1966), Weston La Barre (1968), and Edmund Carpenter (1972) are very brief and go in three different directions with no sense of sustained attention. For instance, Sudnow relates home movies to his ethnomethodological interests in studying social life as it occurs in natural environments as follows:

You can look at films that are made by the member [of a particular society] in a variety of actual natural circumstances and treat these director's productions as data. In this regard, what I have been trying to work with are home movies where we can see the varieties of the ways in which the filmer of the home movies attempts to structure the final product in accord with his conceptions of the phenomena and the interest that the phenomena would have for later recall, later use, and so on [Hill and Crittenden 1968:55].

Another reference to home movies is provided by Weston La Barre when he discusses the relationship between interpersonal eye contact and staring into the lens of a camera:

One of the reasons that watching amateur "home movies" is of ten so uncomfortable or embarrassing is that the subjects, as in a still photograph, look at the movie taker, whom they may know better than the viewer (to his discomfort) knows them-whereas, in professional movies, we are accustomed to the rigid convention that the actor never looks directly at the camera...

The contrast between home and professional movies was brilliantly exploited in one of the Burton-Taylor movies when "home-movies" were indicated very simply and unmistakably by the actors' looking directly into the camera and putting on the self-consciousness of the amateur who knows he's being "taken" [1968:101-102].

Edmund Carpenter mentions home movies in another context. When he discusses the notion of a collective unconscious and corporate images that produce homogeneous patterns in "art" forms, he says:

A Canadian artist recently went on $\mathrm{CBC}$ radio to ask listeners to let him borrow old home movies. He assembled these into a remarkable document-remarkable because it enables us to perceive, with some objectivity, our cliches, our collective unconscious, something otherwise so immediate, so obvious, we can't step back from it [1972:59-60].

Brief references of this nature remain merely anecdotal and speculative at best.

It is important at this stage to distinguish between different types of film that are called "home movies" by some people at first glance. It appears that the label of "home movie" has been attached to a variety of film forms based on notions of such qualities as "primitive," "non-professional," "inexperienced," "naive," "non-narrative," and the like. It is possible to distinguish five categories of these films: 
(1) the "artistic" home movies produced by members of the New American Cinema which may be understood as a kind of Dadaist reaction to Hollywood and to stereotypic Hollywood film products;

(2) the use of raw home movie footage as "documents" in the autobiographical and biographical films, such as Film Portrait mentioned above;

(3) the use of a home movie style in commercially produced theatrical fiction films, as in Up the Sandbox;

(4) native-generated films such as Worth and Adair's Navaho-made films (1972) or Chalfen's socio-documentary films made by groups of Philadelphia teenagers (1974); and

(5) home movies made mostly by middle-class amateurs for family use only.

There is a tendency to confuse the contents of categories (4) and (5) because of the deceiving similar criterion of "nativegenerated film product" with associated qualities of "primitive" and "non-professional." The fact is that neither Navaho Indians nor Black lower socio-economic teenagers make the type of home movies that are being investigated in this paper. ${ }^{15}$

It is specifically the task of this paper to show that a particular arrangement of film communication "events" and "components" distinguish and isolate a unique genre of film called "home movie." The home movie genre explicated in this paper does not include films studied in a "culture at a distance approach" (Mead and Metraux 1953), bio-documentary films (Worth 1965), or socio-documentary films (Chalfen 1972, 1974). These films and the other categories mentioned above manifest different arrangements of events and components, and thus do not belong to the home movie genre.

In summary, this paper concentrates on an unexamined genre of film communication. It appears that little serious attention has been given to the study of home movies as such, as a cultural artifact, as expressive behavior, or as a process of communication in any of the related disciplines of sociology, folklore, anthropology, cinema studies, communication, or psychology. ${ }^{16}$

\section{SOURCES OF HOME MOVIE DATA}

Sources of data for this report come from approaching the study of home moviemaking from four different directions.

(1) "How To Do It" manuals (hereafter referred to as HTDI manuals) and related advice columns and articles on home moviemaking. By examining this published material, I have extracted a set of prescriptive and proscriptive rules for home moviemaking behavior. I have looked for statements that determine what kinds of behavior are considered appropriate within the framework of communication events and components previously outlined.

(2) Approximately 9000 feet of what people have shown me in their homes as their home movies. In addition, the possessor of these films (not necessarily the same as the moviemaker) was interviewed for contextual information that was not available when simply viewing the home movies.
(3) A series of 40 interviews asking what it was like to be an audience for someone's home movies. Primary attention was paid to determining the proper social organization and expected behavior for the exhibition event.

(4) The culling of innumerable popular resources for any kind of reference to home moviemaking. Materials here included daily newspapers, popular moviemaking magazines, camera advertisements, and the like.

The diversity of these approaches is an attempt to compensate for one major shortcoming of this study, namely, an inability to actually observe the complete process of home moviemaking in progress. Observing film communication, as it "naturally" occurs, is a difficult task. In contrast to studying a speech event, film communication requires the observation and description of several different types of events over time. For this study, different parts of the home moviemaking process have been observed, but no long-term participant observation strategy has been attempted.

Readers should also understand that all behavioral examples discussed in this report come from a limited sample of white middle-class subjects. It is not known how other cultures or social groups would respond to the concept of "home movies." Many non-industrialized societies, of course, do not have such a notion at all, while in our society different groups have embraced the technology of the camera, but little is known of how this technology is used or for what purposes.

The descriptive and analytic sections of this report begin with a discussion of film events, followed by film components and a functional analysis of home moviemaking.

\section{HOME MOVIE PLANNING EVENTS}

The conceptual category of "planning" consists of any activity, behavior, or performance in which there is some form of decision, first to use a camera, and second, what to record and how to record it in motion picture images. Thus we may (in some genres of filmmaking) be describing such activity as learning to use the equipment, organizing a film production in terms of getting a director, cameraman, grips, etc., or auditioning actors, making arrangements for on-location shooting, doing historical research, preparing a script, re-writing, and the like.

The study of planning events for home movies, however, reveals the first major difference between prescribed behavior and actual behavior. While almost all of the HTDI manuals recommended some type of planning, subjects admitted to rarely ever doing any. Seldom do extended discussions or debates involve the question of whether to make a movie or not. Shooting scripts or acting scripts are seldom, if ever, written. Subjects said they "just knew" when to get out the camera and buy some new film.

For instance, one home movie manual was organized and written around the notion of planning. An introductory statement read as follows:

No one can produce a successful film without planning it. The only question is when we are going to do the planning. At first, we may leave it until editing, so the first section is devoted to Planning After Filming. Then we see the advantages of Planning During 
Filming... Finally, we become sufficiently experienced to attempt Planning Before Filming, and this is discussed in the third and main section... [Grosset 1963:6]. ${ }^{17}$

Another example comes from an advice column:

How to Plan an Interesting Film.

All it takes is some extra thought. Take Christmas, for in stance. It involves the entire family, and there is plenty of colorful activity. Start by making a list of the activities that your family normally engages in during the holiday. Break this into three parts: preparation, Christmas Eve, and Christmas Day. Now list the events in logical order [Anon. 1968].

... since the key to a good film is pre-planning, and giving some thought to how the final product will look... [the] filmmaker should try to visualize the completed film, and even write a short scenario, if necessary [Smith 1975].

None of my informants said that planning was important. Subjects implied that asking about planning a home movie just did not make sense. ${ }^{18}$ It appears that home moviemakers just "like to do it" and do not treat it as "a production." They just know when to make a movie and want to leave it at that. Planning, it seems, would take the fun out of it.

Thus for this genre of film communication, unlike most others, planning and decision making do not consciously occur before filming begins. Decisions on specifically what to shoot and what to avoid apparently take place tacitly, at the last moment, when the camera is loaded and the cameraman is looking through the viewfinder. Notions of what to shoot, and what not to shoot, however, are hardly random. One's culture and social norms make it tacitly clear that certain events, behaviors, and so on, are to be shown or not shown.

\section{HOME MOVIE FILMING EVENTS}

For analytic purposes, "filming" events must be subdivided into "on-camera" events and "behind-camera" events. Behind-camera filming events are discussed first.

The conceptual category of "behind-camera filming" consists of any activity, behavior, or performance that in some way structures that use and operation of a motion picture camera. Thus we try to include description of a film director's behavior, coordination between director and cameraman, the cameraman's shooting techniques or "tricks," etc.

Another discontinuity emerges when we compare the behavior prescribed by the HTDI manuals and the actual behavior of home moviemakers. In general, the manuals offer a lot of technical advice and strategies for the cameraman. For example, one advice column recommended the following:

Start your shooting with a long shot of your house and a member of the family putting a wreath on the front door. Move in for a medium shot of the person putting up the wreath, then a close-up of the wreath and a ribbon on which you have printed your titlesay "Christmas 1968" [Anon. 1968:134].

Vary your shots. Film Mother entering with groceries, then stop the camera and move to another angle to shoot the bags being emptied. Move to another vantage point for a shot of the turkey being held aloft, then come in for a close-up of a child's face registering delight... you'll have variety and a fast pace [Anon. 1968:134].

However, one manual cautioned its readers:
... if you intrude too much or try to direct too much, it's likely to lose all its genuine flavor, and the results won't have the really memorable quality that spells out B-O-Y [How To Make Good Movies, p. 26; hereafter referred to as HT]

One example of behind-camera behavior characterized by over-direction and intrusion is nicely illustrated by the following cartoon (Figure 3).

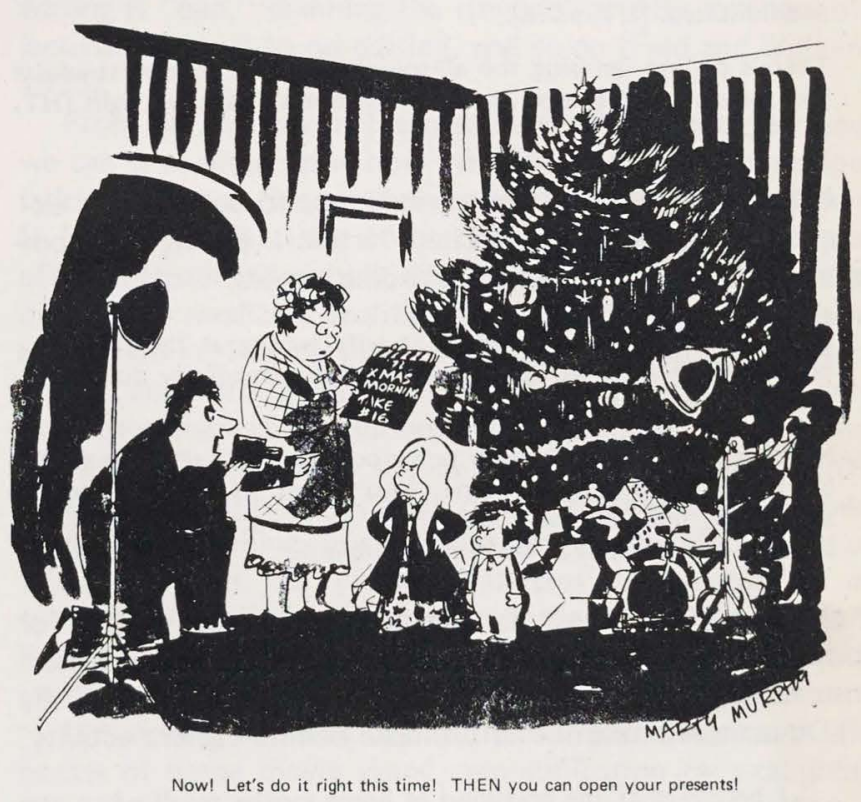

Figure 3

Some of the manuals offered a set of rules to overcome common behind-camera "mistakes." These corrective rules included (1) starting each sequence with an establishing shot, (2) photographing all scenes in a logical order, (3) avoiding excessive panning - pan only when following some action, (4) avoiding excessive use of the zoom lens, etc.

However, the majority of footage viewed for this study ignored all of these "rules." In fact, it appears that disobeying these rules describes the norm for behind-camera behavior. (Characteristics of this norm will be described further in the section titled "Code Characteristics" in the following pages.)

Subjects stated that they did not want to be bothered with thinking about camera techniques-as long as the pictures "came out," everything was fine. Again, as with planning, the HTDI manuals have emphasized an event and components that home moviemakers prefer to ignore.

However, this situation is exactly reversed when we analyze "on-camera" events. This category consists of any activity, behavior, or performance that in some way structures the persons or things that "happen" in front of an operating motion picture camera. Examples of suitable behavior range from how an actor reads his lines to hamming for the camera or how people spontaneously present themselves to a camera, etc.

The HTDI manuals seldom give advice on how to behave while on-camera in home movies. ${ }^{19}$ Both the manuals and 
informants agreed that people frequently act "funny" when home movies are being made. The HTDI manuals describe this situation as follows:

There's something about a movie camera that makes people stop what they're doing and stare into the lens. Or, they may simply wave at the camera [Family Movie Fun for All, p. 24; hereafter referred to as FM].

[When most people] become aware that a camera's unblinking stare is aimed in their direction, they react stiffly, self-consciously, and inhibited. [HT, p. 18].

There's no use ignoring the all-too-obvious fact that most adults feel somewhat ill at ease in the bright beam of a movie light [HT, p. 54].

More advice was offered on how not to behave. For example, one advice column cited "artificial posing as a common reason for "disappointing" home movies:

People just standing in a group, a wife waving at the camera, a child making faces at the camera all make dreadfully dull movie shots [Anon. 1968:132].

Nothing looks quite so goofy as a group of people standing stiffly in the midst of a lively scene. You've got to get them to do something, but you can't leave it up to them; they haven't the slightest idea of what to do [Sutherland n.d.].

The manuals resort to behind-camera instructions for adopting a filming strategy that causes minimal disturbance. Instead of providing information for on-camera behavior, the HTDI manuals continue to promote behind-camera activity.

...I believe that the best kind of home movies result when you avoid being self-conscious about shooting motion pictures. The camera just happens to be around when people are having fun and doing what they like [FM, p. 25].

To capture them un-selfconscious and relatively uninhibited, your best bet is to plan your shooting for occasions when your intended subjects are engrossed in some sort of activity [HT, p. 18].

However, scenes of "natural" behavior were seldom seen in the home movies viewed for this study. Impromptu realities were greatly outnumbered by scenes of hamming or "actingup" for the camera. In general, patterns of on-camera behavior contradicted the behind-camera objectives recommended by the manuals. Capturing an impromptu reality was by far the exception rather than the rule.

Observations made by subjects about on-camera performance also contradicted the HTDI manuals' claim that posing was "dreadfully dull," and that reactions to the camera produced "disappointing results." Instead, viewers generally expressed delight and pleasure when seeing these facial and gestural reactions to being "caught" on-camera. It appears that waving at the lens, making faces, posing stiffly, and the like, are entirely appropriate examples of accepted behavior for this event. Informants openly recalled the fun they enjoyed when they were in the movies rather then shooting the movies.

\section{HOME MOVIE EDITING EVENTS}

The conceptual category of "editing" event consists of any activity, behavior, or performance which accumulates, eliminates, or rearranges film in a specific order or sequence after it has been exposed and chemically developed, but before it has been shown to an audience. Activity appropriate to this category includes everything from simply cutting off film leader to the making of $A$ and $B$ rolls for the multiple production of prints, constructing optical dissolves, cutting in frames of stop action, and so on.

Editing in this mode of visual communication represents the fourth non-overlapping example of prescribed behavior versus actual moviemaking. Almost all of the HTDI manuals promote some form of editing from the home moviemaker. Editing is given as much attention as planning and shooting the movie. For instance, one advice column stated that moviemakers just don't take advantage of editing's potential:

This is an all too frequently neglected aspect of home filmmaking, yet with just a few cuts and splices any film can be made to look better... To edit is first to remove, then to rearrange, then to remove once more [Smith 1975].

One of the HTDI manuals stated:

Most movie makers hesitate to change the order of scenes, feeling that it is a little like changing the truth. Not at all. If changing the order of scenes from the way you shoot them helps to make your movie more interesting and informative you're actually making the truth stronger [FM, p. 79].

In actuality, however, most home moviemakers were extremely reluctant to do any editing at all. Few attempts were made either to cut out poorly exposed (or even unexposed) footage or to rearrange shots within one roll of film. ${ }^{20}$ When some form of editing was observed, it generally meant cutting off some excess leader at either end of the 50 -foot roll and splicing two or more rolls together. The motivation for this accumulative "cutting" was simply to produce a movie that would take a longer time to show on the projector.

Again, home moviemakers stated that they just did not want to be bothered with cutting and "glueing" pieces of film; it was hard enough to keep all of their reels of movies in order, "never mind fooling around with individual shots." Thus actual home moviemaking behavior does not conform to the prescribed behavior offered by the manuals and advice colums. ${ }^{21}$

\section{HOME MOVIE EXHIBITION EVENTS}

The last event category under examination is "exhibition." This conceptual category consists of any activity, behavior, or performance in which film is shown and viewed in a public context. "Public" contexts do not include the viewing of rushes or edited work prints on a viewer or a projector by the filmmaker or editor alone. These activities are classified as "private" showings and are better categorized as editing events. Exhibition events may occur in many settings, such as a downtown movie theater, a classroom, a drive-in theater, or a livingroom.

A comparison of the emphasis put on exhibition events by both the HTDI manuals and moviemakers reveals another set of differences similar to those that were observed for oncamera events. The manuals have little to say; the home moviemakers a lot. ${ }^{22}$ 


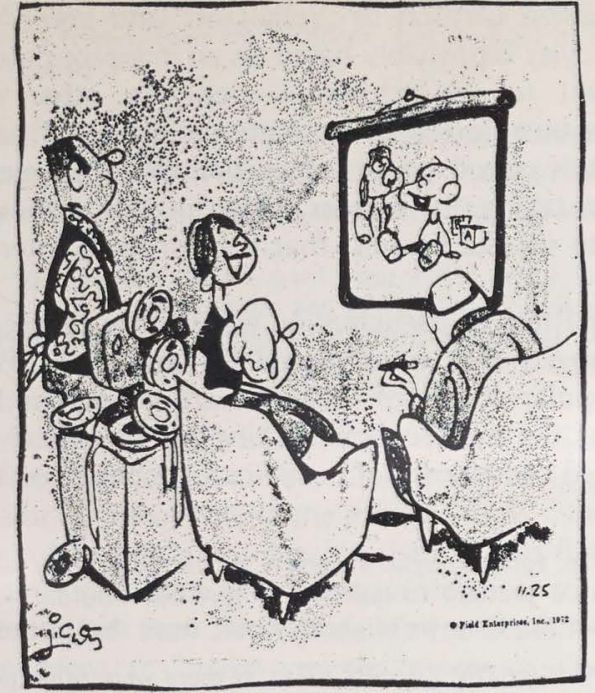

"It's a preview for a few select relatives before it goes on general release to friends and neighbors!"

\section{Figure 4}

In one rare exception, one manual offered the following advice in a section titled "How to Stop Torturing Family and Friends:"

Consider your audience. The lights are extinguished and everyone settles back to enjoy your movies. They aren't permitted to settle very far or very comfortably though, because four minutes later... on will come the lights again while you rewind and thread a new roll through the projector. This spasmodic sort of performance is upsetting to the digestion, not to mention what it will do to one's temper [HT, p. 92].

This remark was actually directed toward editing activity. Home moviemakers were advised to lengthen their reels of film by splicing rolls together to make a longer screening time. ${ }^{23}$

For most home moviemakers, exhibition events are very exciting times. Informants reported that home movies are usually shown in a party atmosphere, not too unlike the situations that originally inspired the shooting of the films.

In summary, a consistent non-overlapping pattern of emphases has emerged for the five categories of film communication events under examination. The reciprocal pattern of emphases may be schematically represented as follows:

\section{Event}

(1) Planning

(2) On-Camera Filming

(3) Behind-Camera Filming

(4) Editing

(5) Exhibition

\section{Prescribed Observed} Behavior Behavior

$X$ denotes occurrence or emphasis of event behavior

$\mathrm{O}$ denotes non-occurrence or non-emphasis of event behavior ding to perform this communication event bears little resemblance to actual behavior exhibited by moviemakers in the home mode. The HTDI manuals promote the creation of a symbolic environment that emphasizes manipulation of a reality. Home moviemakers, however, stress the use of filmmaking technology to symbolically record, document and reproduce a reality. It is interesting to note that the "naive" home moviemaker embraces the view of filmmaking often promulgated by social scientists of certain schools, i.e., that editing is "bad," planning the subjects' activity is taboo, objectivity is equal to no editing, and so on (Feld and Williams 1975).

From an analysis of the communication events involved, we can thus understand how the notion of symbolic manipulation applies to this particular genre of film communication. It is obvious that any form of mediation lends itself and often determines symbolic manipulation of some kind. Technologically mediated realities allow for differing sources of manipulation. For instance, behind-camera events, on-camera events, and editing events offer different, but not mutually exclusive, chances for symbolic manipulation. Not all forms of film communication use or emphasize the same events. Patterns of emphasis separate one film genre from another. Home moviemaking, in contradistinction with Hollywood or television films, for example, stresses a manipulation of symbols primarily in on-camera events and ignores opportunities in both behind-camera and editing events. This pattern is unlike most other genres of film communication.

It is now possible to characterize further the process and events of home movie visual communication by examining the second dimension of my previously described scheme, namely, the film communication components. In this way, the symbolic manipulation and the nature of the symbolic reality created for this film genre will become clearer.

Ideally, each component should be examined in relationship to each event. Since we have already established that on-camera and exhibition events are most important in home moviemaking, we may limit our discussion to these events and their relevant components.

Each component should also be examined for its relationship to the component message form. "Home movie" is the filmic message form being examined for a systematic configuration of relationships with other components. In this sense, "home movie" is a recognized style characterized by (1) a limited list of "actors" and "actresses" 24 (participants); (2) repetitive scenes of certain activities involving certain themes (topics); (3) a restricted set of places where the movies are shot and later shown (settings); and (4) a habitual use of camera techniques, juxtaopositions, and style (code). The set of patterned relationships that emerges from componentevent interactions defines home movies as a genre of film communication.

The next section explores specific characteristics of the home movie pattern as it was revealed by both the HTDI manuals and interviews about actual home moviemaking.

\section{PARTICIPANTS IN HOME MOVIEMAKING}

Examination of the component "participants" is a convenient starting point. The category includes anyone ${ }^{25}$ who
In other words, the process of visual communication that has been extracted from the literature addressed to those inten- 
participates in an activity (therefore any event) for which the central organizing concern is to produce motion pictures. We must look for patterned relationships between those people who do participate and those that do not.

First of all, it is very clear that the majority of home movies contain pictures of people. Both the HTDI manuals and actual home movies agree on this point. Almost all shots contain people rather than things-with the exception of the commonly seen household pet or animals in other contexts. One moviemaker told me:

\footnotetext{
.. Almost never is there not a face-99\% of the time. That's just the way we operate: we think film is too expensive to expend it on non-people, or, unless it has some historic value, it has nothing....
}

The HTDI manuals frequently stated who should be included in the movies. An informal inventory of participants appropriately included in on-camera events appeared as follows:

Good movies ... are entertaining. It's fun to see movies of picnics, vacations, ski outings, and badminton games when they involve friends, neighbors and relatives [Better Movies in Minutes, p. 39; hereafter referred to as $\mathrm{BM}]$.

Add color, depth, and interest to your scenic movies by including friends or family members in the foreground [BM, p. 23].

Thus, according to the prescribed norm, the community of participants appeared to be limited to immediate family members, relatives, close friends, and neighbors (the close friends do not have to be neighbors, but the neighbors have to be close friends).

A similar inventory of participants was prescribed for home movie exhibition events. A consensus of agreement was found in all HTDI manuals. For example:

... shooting film that your family, and your friends will enjoy looking at [FM, p. 5].

... how skillful you become in taking movies that your family and friends really enjoy watching [Now That You're in Show Business, p. 1 ; hereafter referred to as NT]

Good movies ... are fun to see and fun to show next month when friends and relatives drop by [BM, p. 9].

... that will make it repeatedly enjoyable not only to you, yourself, but to the audiences of friends and relatives who'll also want to see [HT, p. 9].

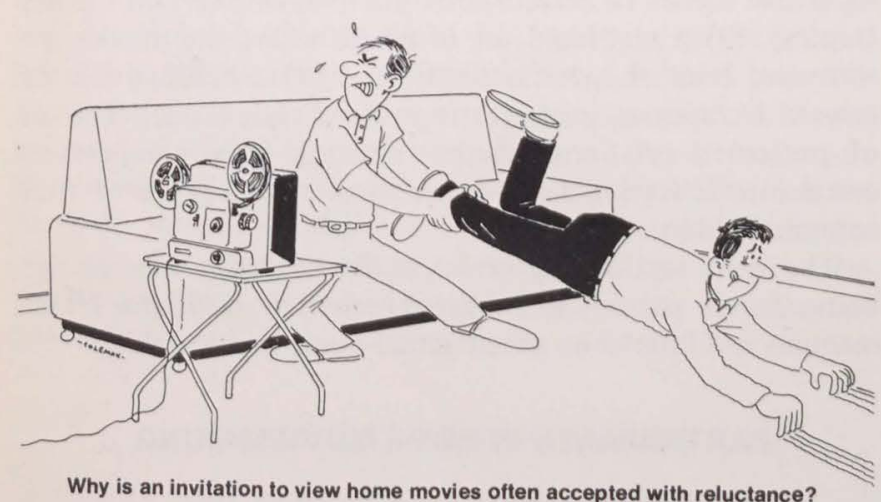

Figure 5
The frequent cartoon of "reluctant" and bored viewers of home movies is probably based on an inappropriate choice of participant for an exhibition event. In other words, the viewer is outside the appropriate collection of participants.

It is this closed system of participants-the people named as either taking the movies, being in the movies, or being invited to see the movies-that is of primary interest to this analysis.

This pattern of participation was strictly adhered to in the home movies that were viewed for this study. By far, the most popular choice of subjects were young children in the family of the moviemaker. Asking informants if and when this closed community of participation could ever be broken, I was told:

... If an aunt brought a person to the party that we all didn't know, l'd pretend to take her picture but wouldn't-didn't want to waste the film; we're cheap, yeah, done that lots of times....

... It was strictly a family event; if there were other people in the movie it was just because they were there at that time ....

This attitude was very obvious in the movies. The camera seems to tolerate the "other" people in scenes of crowded places (especially beach and amusement parks). However, the camera does not attend to unknown people as it does the central characters of the home movie community.

Thus one important common denominator of most oncamera participation is that people are personally known to the home moviemaker. One piece of moviemaking advice incorporated this theme:

Actually there's no limit to the subject matter you can shoot with your camera. But for this first movie choose something or someone you know quite well [FM, p. 11].

It was clear when viewing home movies that relatives, neighbors and close friends' friends not known by the moviemaker were unlikely choices for on-camera participation.

The pattern of appropriate participants is further clarified when we consider other people who are known and who regularly interact with different family members, but do not appear in movies. For instance, home movies can include the family doctor, the mailman, the paper boy, delivery men, trash collectors, metermen, and the like-but they don't. Inclusion of these people is highly unlikely in spite of their regular appearances "at home." On the other hand, family relatives (especially favored relatives) are likely to be included because of their regular but infrequent appearance at home.

Several other characteristics of appropriate on-camera participants further reveal the pattern. For instance, participants are almost always awake, ${ }^{26}$ never naked (except for young children), and almost always in good health. People who are ill and bedridden with a communicable disease or a broken limb are generally not included. ${ }^{27}$ One does not see a person vomiting in home movies. Participants are always alive; dead people are not appropriate subjects for home movies. ${ }^{28}$

Determination of which participant is designated as cameraman must also be considered. In nearly all cases investigated for this study, the male head of household used the camera most of the time. In a few cases, a teenage son, who was learning about cameras and filmmaking, took over this responsibility. One HTDI manual acknowledged the situation as follows: 
Good news for you Dad! Your... camera can be operated easily by Mom, a friend, even the children. Let Dad get in the movies too! [NT, p. 9].

In actuality, however, the rule was that Father participated more in behind-camera events than in on-camera events. Another piece of advice suggested the following:

By the way, if you should want your entire party in the same scenes... just set the camera and ask a friendly-looking by-stander if he'll do the shooting. You'll hardly ever get a turndown [HT, p. 36].

There is more flexibility in letting someone unknown, yet "friendly-looking," take the pictures than having a stranger share a major or minor role in the movies.

Thus, another important characteristic of this film genre is the expressed importance for most participants to appear in the movies rather than be responsible for actually shooting the movies. Here, to "make a movie" means to appear in the movie rather than shoot the movie, set the camera, decide what to shoot, etc. ${ }^{29}$

In summary, the community of participants in the home movie genre is a relatively closed system. The list of people who are invited to participate is quite limited and unique. It is not the case that anyone can be in any home movie. The narrow selection of participants is perhaps most clear in exhibition events when only family members, relatives, close friends, and neighbors-who are usually in the movies-are invited to see the films. Participants in on-camera events are limited to a similar grouping of people. This choice is further regulated by the cameraman who is usually the male head of household.

Another aspect of symbolic manipulation has been reinforced from analyzing the participant component. Much more attention is given to appearing as an on-camera participant than in a behind-camera role. In this sense, the presentation of oneself and manipulation of oneself are more important than controlling and manipulating the symbolic content from behind the camera. This finding corroborates results of the event analysis presented earlier.

\section{TOPICS OF HOME MOVIES}

Examination of the "topic" component in conjunction with home movie filming events further develops a profile of patterned social behavior. Topic describes film content in terms of themes, subject matter, and activities that are filmed and later shown in a movie. Topic is usually described by answering the question: "What was the film about?"

Readers should be aware that present camera technology allows pictures to be taken of nearly anything, regardless of excessive movement, varying light conditions, size of subject matter, and so on. This is equally true for professional filmmaking equipment as well as the less expensive cameras usually used for home moviemaking. Advertisements for popular cameras encourage camera use "anywhere." However, examination and comparison of the HTDI manuals and home movie footage reveals that actual use of cameras is relatively restricted to sets of appropriate topics and themes. For instance:
Movies are best and most interesting when they show people actually doing things rather than merely smiling or waving at the camera. A baby's first awkward steps, your family's vacation activities, a friend on water skis-these are the kind of subjects that make memorable movies [HT, p. 8].

How much would it be worth to you in ten, fifteen or twenty years to be able to relive today... see your children as toddlers... watch your family through all their happy times... on Christmas morning .... at birthdays... graduations... on family vacations... on visits to grandparents...to keep a complete filmed record of your family's life together? [emphasis added] . ${ }^{30}$

Other good subjects for family movies are parties, a class day at school, feeding a new pet, building a tree house, making a snowman, a child painting a picture, building a model-in short, any activity that shows the family in the process of living and growing [Anon. 1968:134; emphasis added].

Good movies are especially great in a few years when you want to relive a trip to the lake, the shore, or to the big city; the snowball battle the kids had after the blizzard of '68; Johnny's first birthday and his first steps; the day you got the new station wagon; the Easter-egg hunt-it's an endless list [BM, p. 9; emphasis added].

As I will show below, the patterns of prescribed behavior and observed behavior are once again dissimilar. The HTDI guides and advice columns frequently suggest "a complete filmed record" of family life or an "endless list" of suitable subject matter. For example:

When a boy meets a bologna sandwich, especially small boy and large sandwich, the movie potentialities are measureless. Children at meal time are first-rate movie subjects ... [HT, p. 54] .

Once there was a brother and a sister... (who took a bath) and left their bespattered parents amused, exhausted, and totally unconscious that such carryings-on make wonderful home movies [HT, p. 43].

An extreme example appeared in an advice column entitled "A Good Home Movie Is Not Necessarily 'Well Made" ":

...there are nevertheless dozens of dreary routines that you might someday be glad you filmed... Your route to work, your friends' houses, the same old tennis court, a plain old street bus ... [Sutherland 1971:122]. ${ }^{31}$

However, the list of topics that home moviemakers actually do record is not endless. The selection of topics that the home moviemaker can make and the actual list that he does make do not coincide. The actual list of preferred topics and themes appears to be quite restricted and limited.

While we might expect "home movies" or "family movies" to be mostly concerned with family life at home, it appears that only a small fraction of everyday life is recorded on film.

Several broad categories of topics were found to be the most appropriate choices for home movies. The following listing has been developed from a frequency count of topics seen in the actual movies studied for this report.

(1) Vacation activity is very well represented. For instance, home movies contain many scenes of children at the beach or the lakeside during summer vacation. Camping and boating activity are frequently seen along with swimming and bicycle riding. Children regularly appear in various play activities-floating a toy sailboat, chasing a ball, climbing a tree or on swings, or in other activities where a lot of action and movement is involved. 
(2) Holiday activity frequently demands use of a movie camera. For instance, home moviemakers are likely to include images of the Christmas tree or of the family opening presents, Thanksgiving dinner, an Easter-egg hunt in the backyard, or colorful Halloween costumes.

(3) Special events in the lives of family members (especially children) are frequently included in home movies. Examples here include a christening, a birthday party, a trip to an amusement park, graduation day, a parade with a family member involved, a wedding party, and the like.

(4) Local activity will also be filmed when slightly unusual events are taking place. For instance, home movies are likely to include scenes of snowball throwing, lawn parties, a baby learning to walk in the driveway or playing with garden flowers. Children and adults are frequently seen showing off something new such as a new toy, bicycle, or car. Family pets are also regularly filmed when playing with family members, chasing sticks or balls, and so on.

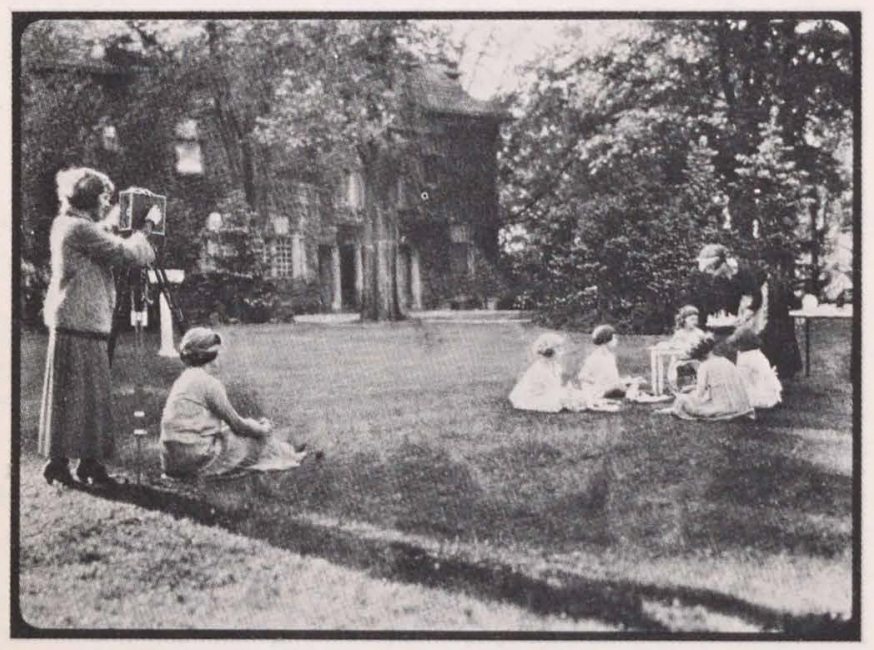

Figure 6 -making home movies, 1923

The pattern is further clarified when considering the many activities around-the-house that are not included as appropriate topics for home movies. For instance, one seldom, if ever, finds family members preparing, eating, or cleaning up from breakfast, lunch, or dinner in these movies. On the other hand, we do find that a "special" meal will be filmed such as Thanksgiving dinner, a birthday meal, a meal at a wedding reception, or a summer barbacue when relatives, neighbors, or friends are present. We never see people getting dressed in the morning or getting undressed and going to bed at night; we never see family members going to the bathroom to either wash or use the toilet, though young children infrequently appear in bathtubs. We never see children going to school or father or mother going to work. We never see scenes of washing dishes, cleaning house, or doing house repairs (other than a major renovation). We never see family members reading a book or magazine, watching television, listening to records or to the radio, or writing a letter. We do not see scenes of children being scolded, family quarrels, or lovemaking.
In summary, it seems to be the case that the list of excluded topics is endless, rather than the included ones. The obvious conclusion is that what is supposed to be a documentation of daily family life, isn't at all. Rather than finding that anything can be filmed, we find a very selective choice of topics.

\section{SETTINGS FOR HOME MOVIEMAKING}

Much of the analysis of topic selection is relevant to examining choice of setting. The conceptual category "setting" can refer to two different things. In some cases, setting describes the specific times and places when and where a communication event (such as planning, filming, editing, or exhibition) takes place. In other cases, setting may refer to the times and places that appear as the content of the movie. ${ }^{32}$ In the home movie genre, it is highly likely that a description of the setting for the filming event coincides with a setting description of the scene in the movie. For instance, film shot at a beach shows scenes of action that actually did occur at the beach. Just as participants do not disguise themselves to "play" a fictitious character, settings are not radically changed for appearance in home movies. ${ }^{33}$

Readers should understand that for most of this analysis of the topic component, I held the setting variable constant -namely, "at-home." However, it appears that not all settings at home are appropriately included as home movie content. First of all, outside-home settings are much more common than indoor settings on roughly a ten to one ratio. When filming inside a home, moviemakers seldom used their cameras (and lights) in bedrooms, bathrooms, attics, cellars, or kitchens. Thus it is not the case that any setting in or around the house can be used. Home movie settings in this context are usually restricted to livingrooms, diningrooms, and backyards. ${ }^{34}$

While the home setting is frequently used, this setting usually requires another special element. Christmas day, Thanksgiving dinner, an Easter-egg hunt, or relatives visiting to see what the new baby looks like might provide this additional element. Something must intrude, such as a snow storm or a hurricane, to change the common appearance of the home setting. In this sense, home movies do not record the reality of everyday life. Instead, we find a carefully selected repertory of highlighted times and occurrences that a family is likely to celebrate and wish to remember.

Another category of home movie settings might be labelled "away-from-home." On an everyday basis, family members leave their homes for various reasons. However, very few types of away-from-home settings include a filming event. In general, only three types of social activity are important to this context, namely, trips to the home of a relative (or very close friend), special events, and vacation trips. The first group conforms to at-home characteristics previously described. The second category of special events frequently takes moviemakers away from home and includes a graduation in a school auditorium, a parade in a city street, a wedding reception, and so on.

Home movies made in the third context are sometimes called "vacation movies" or "travel films." These movies usually document "special" places such as a wildlife preserve, a zoo, a historic site, a national park or landmark, an Indian 
reservation, or a natural "wonder" such as Niagara Falls. ${ }^{35}$ The majority of these films are made during vacation times. When vacation consists of staying at a seaside cottage, a mountain retreat, a wooded camping spot, etc., topics are filmed that would not deserve attention when movies were made at home. For instance, at a vacation setting, home movies are likely to include common everyday activities such as riding a bicycle, getting wet in a backyard sprinkler, playing catch or frisbee, or just roughhousing on the ground. In this respect, topic choice for filming events co-varies with setting choice. Topics and activities common to everyday life at home are more appropriately filmed away from home.

Selection of setting also includes a consideration of time. If we ask what periods in a human's life or what social situations we choose to record in home movies, we find evidence for a conventionalized pattern of selection. Filming events occur during the first days of an infant's life, or a baptism, during early birthdays, at confirmation and Bar Mitzvah parties, during graduations, weddings, anniversary parties, and the like. On the other hand, we do not find scenes of the last days of life or of divorce proceedings.

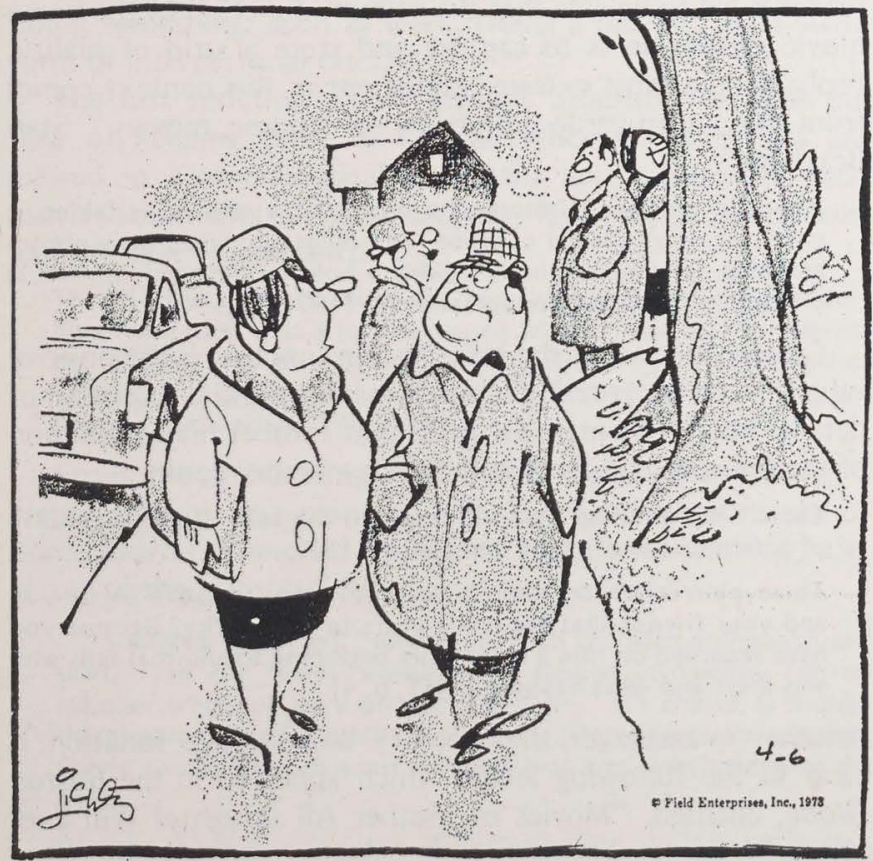

"I had no idea they were going to show us home movies of their divorce evidence against each other!"

Figure 7

Description of setting also includes where the exhibition events take place. This is perhaps the most distinctive characteristic of all home movies. In all cases investigated, home movies were shown in a livingroom or a recreation room of a private home. Home movies are almost never shown in movie theaters, in school auditoriums, in drive-in theaters, or other public exhibition settings. Only rarely will such a film be shown in a film festival or museum collection. ${ }^{36}$

In summary, we see that home moviemakers do not arbitrarily select any person, any activity, any site, or any time to use their cameras. $^{37}$ Rather than a random or haphazardly chosen set of participants, settings, and topics, we find a relatively limited selection of subject matter that is all positively (versus negatively) valued. The symbolically created world of home movies is a very happy place, full of smiling people engaged in enjoyable and important activities.

\section{CODE CHARACTERISTICS OF HOME MOVIES}

The last film component to be discussed is "code." A description of a code includes the elements or units that define a particular message form (or style)-in this case, the message form of home movie. Analysis of code includes both the description of filmic habits, conventions, or filmic routines (in shooting and/or editing) and a description of social habits and conventions when they are patterned. For instance, we may be describing a particular sequential ordering of shots as well as a pattern of on-camera social behavior, such as people always looking at the camera, or people always wearing new or clean clothes, etc. While it is easy to label a film "like home movies," a description of its code allows us to specify what kinds of behind-camera and oncamera behavior determines this recognizable style.

The following patterns appeared with highest frequencies, although the HTDI manuals are quick to warn novice movie makers about these as "mistakes."

(1) In general, there is a great deal of camera movement and a strong tendency to pan. Frequently, the camera tries to follow pieces of action and to stay with whatever is moving or doing something. In scenery shots, panning is equally extensive. Frequently, the cameraman tries to cram as much into the picture as possible.

(2) There is a frequent use of the zoom technique. The majority of the newer cameras have a zoom lens built into the camera body, and home moviemakers use the zoom lenses with which they are provided.

(3) The majority of shots in home movies are "long" and "medium" shots. Close-up shots are rare, but more common in the most recently made films. The tendency is to draw back from the subject matter, leaving the central concern (person, place, thing, etc.) of the shot rather small in the overall picture. Standard compositions most often include a great deal of "empty" space around the objects of central concern.

(4) More footage is poorly exposed in older home movies than in the recently made films. Automatic exposure meters have been built into the newer camera models. Of the poorly exposed footage, more footage was under-exposed than over-exposed.

(5) Lengths of shots in a home movie vary greatly. The older cameras were spring wound; this regulated the maximum length of any shot. Most of the newer cameras are battery operated. Now one movie could consist of two 25 foot long shots ${ }^{38}$ or, with the cartridge loaded cameras, one 50 -foot shot. However, this seldom if ever happens.

(6) The shots contained in any 50-foot reel of film seem to begin and end anywhere, with little visual continuity and no apparent conventional order of appearance. The shots were not necessarily related to one another beyond the fact that they were shot in the same place, about the same thing, at the same time, or that they were all shot by the same 
person. There was little if any attempt to structure a sequence of shots in terms of storyline or plot. ${ }^{39}$ The possible structures other than conventional narrative or story have yet to be explored. But it seems clear that people making home movies do not make them randomly. They are, however, following a pattern that doesn't seem to conform to that of other pictorial genres.

(7) The same 50-foot roll of film will sometimes contain shots from several shooting sessions. Different locations or times of shooting were not separated by any visible marker such as a short piece of unexposed film or blank leader.

(8) Jump shots occur very regularly. Rather than a flow or conventional blending of shots into "smooth" sequence, the shots of a home movie tend to jump around, and to appear to be "rough," "jumpy," and not smooth.

A description of code also includes a repetitive pattern of characteristic behavior for on-camera performance. The following elements or tendencies reappeared in each sample of home movies viewed for this study. Each of these tendencies was often mentioned in interviews as "common things that happen in home movies."

(1) There is a lot of waving at the camera. This seems to be appropriate when the cameraman says, "okay, do something," or "move!" People will also wave when they first realize that the camera is taking pictures.

(2) Very frequently one sees people, especially children, walking directly toward the camera, sometimes directly into the lens.

(3) There is an extraordinarily large amount of just staring into the lens of the camera. (Recall the reference to staring by Weston La Barre included earlier in this paper.) People look as though the camera is going to make some form of acknowledgment. This staring is similar to the looks of people sitting for still portraits.

(4) People will strike a pose or present a "camera-face" for an operating movie camera. Subjects will project themselves as the camera watches.

In part, it is this collection of behavioral traits for both behind-camera activity and on-camera appearances that people refer to when they say "it looks like a home movie." In almost all cases, however, a "rule" can be found in the HTDI manuals that contradicts these "natural" tendencies. It must be concluded that the HTDI manuals are promoting the production of a different style of film, and, in turn, a different pattern of film communication.

\section{FUNCTIONS OF HOME MOVIEMAKING}

The final task of this report is to examine the social functions of home moviemaking. An understanding of the relationship between the suggested components and events can be considered along a functional dimension. Aside from initially asking why home movies are made at all, we can also examine what people do with their private use of this media technology, and what this enterprise does for the people involved. ${ }^{40}$ In this case, we can use three sources of data: the HTDI manuals, interviews with participants, and the analyst's observations of the films.

The HTDI manuals were quite helpful in exploring a functional dimension. When asking why home movies are made at all, we find the following:
Few people enter upon movie shooting out of any fatal fascination with the photographic details of it. Usually the impetus is the single desire to preserve things ... [HT, p. 18].

With a movie camera... you can preserve the entire event, unfrozen and continuous, exactly as it happens [HT, p. 7].

What makes it [a home movie] worthwhile is seeing the event replayed on the screen, getting yourself hurled back to something you'd wanted to preserve [Sutherland 1971:123].

The first group of functions focuses on the idea of preserving a piece of experienced reality. The ideal is to "capture" a slice of time and possess it forever, to be able to retrieve it and re-experience it at any time.

The preservation function is predicated on a "capture of reality" theme regularly expressed in the HTDI manuals.

...you'll find much to your pleasure, that you've captured a wonderful slice of childhood, complete and continuous... [HT, p. 9].

Inside your camera, imprisoned on the film and ready for processing, is a truly documentary film story of the cookout, just as it happened [HT, p. 23].

Just point the camera at your subject, press a button, and "capture moving subjects on film." That's all you have do! [NT, p. 2].

In very cogent, persistent, and persuasive terms, the HTDI reader is led to believe that the primary function of the home movie enterprise is to capture and store a strip of reality. Probably the most extreme statement in this context comes from the avant-garde filmmaker of "home movies," Stan Brakhage:

When an amateur photographs scenes of a trip he is taking, a party, or other special occasion, and especially when he is photographing his children, he is seeking a hold on time and, as such, is ultimately attempting to defeat death [1971:24].

Closely related to the preservation function is the positive value placed on creating a visual memory and a retention of details. The HTDI manuals stress that another major function of the home movie genre is that of a memory bank:

There's just nothing that will recall all the color, fun, and reality of good times like a good home movie [BM, p. 1].

These nine sequences were a beautiful story that will please you and your friends that see it for years to come. Why? Because you have recorded on film a story from beginning to end that tells who was there and what happened [NT, p. 4].

Another example of the memory and storage function is clear in the following letter, which appeared in the Boston Globe, entitled, "Movies of Mother All Daughter Will Ever Know."

Dear Killing Me Softly-

... A bizarre and tragic accident took the life of my eldest daughter, 27, last summer. She left a husband and three young children, two boys, 8 and 6 , and a new baby daughter, only 5 weeks old ... I don't think our memories should be let go, unless they keep us from functioning among the living. I have some marvelous movies of my daughter, starting when she was 4 years old. This is the only way her little girl will ever know the kind of person her mother was. I am extremely thankful that I stuck to my movie-making so faithfully. It comforts me to bring back the happy memories.

Signed-Can't Help Singing [June 6, 1975]

Occasionally the prescribed behavior for home moviemaking combines the theme of a visual memory with a pragmatic emphasis on making an investment. 
You've got an investment in every 50 feet you shoot. It's not only an investment in money... but one in memories. Every roll you shoot probably has a dozen things on it you'll want to remember... Actually that film is rather precious [FM, p. 73]

Shooting home movies is like making a good financial investment-you give up something at the time, but you get a profitable return later. And like most good investments, this one grows as time passes [Sutherland 1971:123].

The HTDI manuals also speak of a hedonistic function. "Good times" frequently require some form of photographic recording. Not only should one have a good time making the movies, but viewers should be able to repeat and re-experience these pleasurable times. The hedonistic function plays a large role and is expressed as follows:

This is a book about movies. Not the LIGHTS-CAMERA-ACTION kind of movies, but the kind of personal movies that we make so that we can enjoy our good times over and over again, as often as we like [BM, p. 1].

... whenever you place your eye in the viewfinder, if you think primarily in terms of recording natural, interesting activity, your films will become a marvelously rewarding, continuing source of deep pleasure [HT, p. 8].

What is neglected in these statements is the basic drive in most of us to see ourselves performing, either in terms of doing something, such as work, riding a bicycle, or in some form of interpersonal interaction.

The last function which attracts attention involves the idea of keeping track of change. When home movies are viewed in a chronological order, the juxtaposition of each movie documents changing settings, fashions, people's looks and the like. For instance:

They [home movies] spark the surprising and sometimes disturbing realization that a lot has passed without our having noticed; the gradual changes imperceptibly mounted upon one another .. We're reminded how we used to look, think, live, and behave ... [Sutherland 1971:180].

From the small sample of people that I interviewed, I found general agreement on the functional importance of home movies. The most frequently mentioned was the "triggering of the memory" function characterized by:

... Someone might say "oh look at such and such doing such and such," and the family would make general comments-"oh remember when we were driving past there." It's almost as though the pictures would sometimes serve as a triggering device and then they'd come out with some incident that was associated with the trip....

We must also consider functions not served by home movie production. An idea of ten mentioned in the interviews was that home movies were not an outlet for artistic expression. Just as there would be little artistic motivation when making a tape recording of something, there was little or no concern with making a home movie in an "artistic" manner.

The concern was with documenting an activity or a place:

... It's for a record and they think because it's moving it's more of a complete record than stills would be ... [they] want to document what went on; no artistic impulse....

In the home mode, people make and see "movies" rather than "films" or "cinema." I would speculate that for the home moviemaker "to make and do art" means to tamper with or alter the images of reality. Results of this meddling activity do not reproduce the whole truth or an accurate rendition of reality. Since the emphasis in home movie-
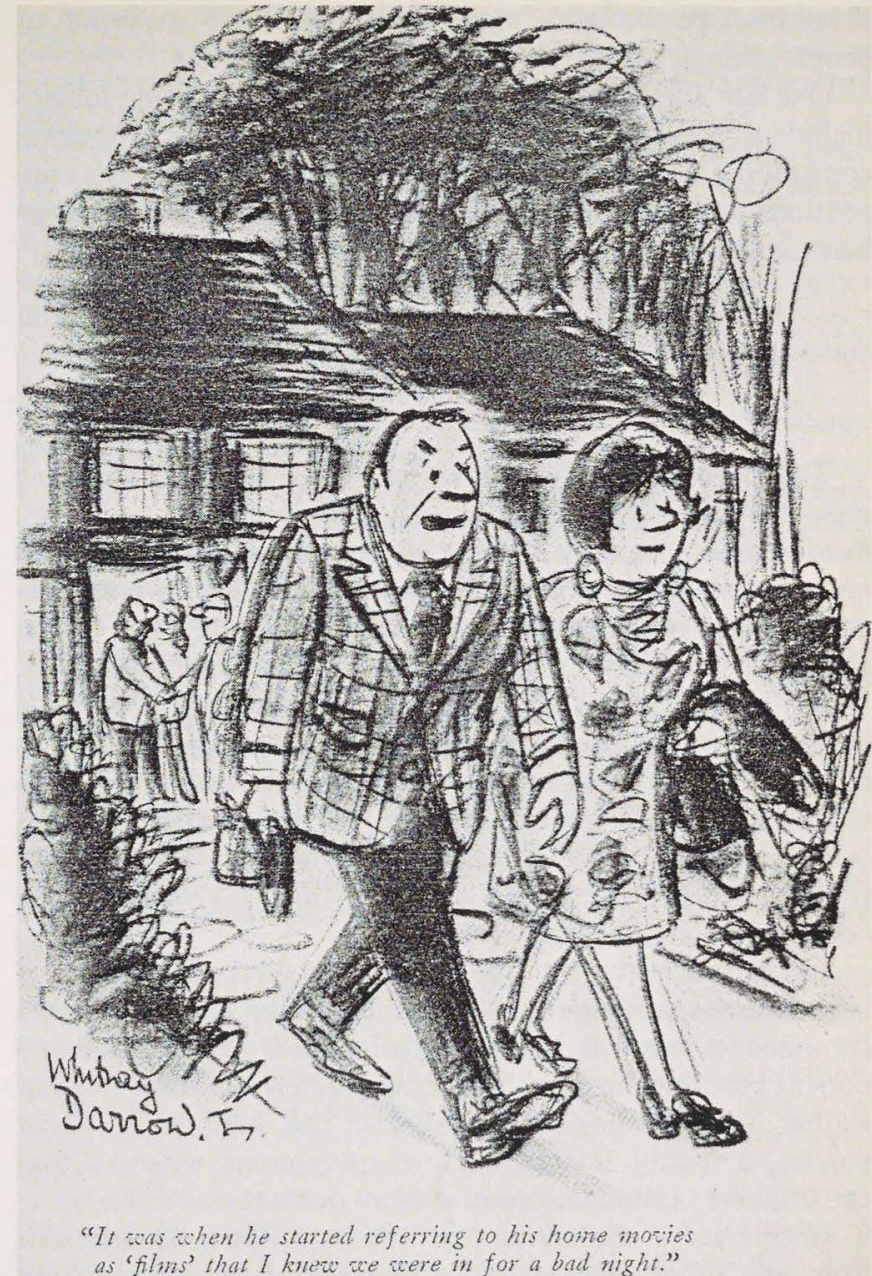

Figure 8

making is to accurately duplicate reality in all its living color, any attempt to alter a copying ability somehow profanes the purpose of the medium.

So far, I have discussed functions that are frequently mentioned in either the HTDI manuals or the interviews organized for this study. However, another group of functions are less clearly articulated but equally important. This collection of functions is best understood when one examines the position of home movies within the entire process of film communication.

When analyzing latent functions, we see that the making and showing of home movies tends to act as a bonding agent creating a specific social structure. Whether this structure is based on kinship ties, neighborhood relationships or close friendships, home movie activity offers visual evidence of specific relationships and both allows and offers future social activities to reinforce these ties. I have noticed that the same people tend to be involved in each of the filmmaking events. In both filming events and exhibition events, specific relationships are re-established, reified, and celebrated. In this sense, these film events illustrate the function of communion. Certain people, representing a specific set of social rela- 
tionships, are brought together to re-affirm an order of people, things, values, perspectives, and worldview.

One can further speculate that functions of home movies include a form of socialization, a maintenance of a behavioral conformity, and a validation of culture. ${ }^{41}$ This suggests connections with the role of myth and other forms of expressive behavior operating within cultural contexts.

\section{CONCLUSIONS}

The purpose of this paper has been to examine home moviemaking as a process of visual communication and home movies as a culturally structured product of symbolic manipulation. A scheme of film communication events and components has been described and used to isolate a set of distinctive characteristics of one genre of film communication.

In the first part of the paper, a comparison was made between a paradigm of communication prescribed by a series of home moviemaking manuals and a pattern found by observing actual moviemaking behavior. From identification and comparison of a series of film communication events, it was found that the prescribed paradigm did not describe the norm for observed behavior.

In the second half of the report, the symbolic content of home movies was examined. A series of film communication components was introduced to delineate a set of event-component relationships that further characterized home movies. Rather than finding that anything can happen in home movies, a highly selective set of preferences emerged that controlled a limited choice of subject matter.

In one sense, the content of home movies is no different from any other form of visual representation. All mediated forms of reality are, in essence, symbolic representations; and all visual forms are a result of a process of symbolic manipulation. In no case is every thing shown, and in no case is the visual symbolic form equal to the "real thing." Thus each form is a result of a decision making process (implicit or explicit) that controls the selection, use, and manipulation of symbolic items and events. It seems clear that different types of visual recording modes, media, and codes emphasize different parts of the overall process of representation.

It has been shown that home moviemaking, as one type of visual recording, de-emphasizes the manipulative potential of the recording technology. In this sense, home movies stress a documentary function in order to produce a copy of a familiar reality. Again, however, it is not the case that everything is shown or that anything can happen. One purpose of this study has been to outline the out-of-awareness dimensions of symbolic manipulation that produce the world of home movies.

The structure of the criteria of selection and manipulation rule out the possibility that home movies document a reality of everyday life. Instead of a fabricated reality common to most feature-narrative films, used in a context of mass communications, we find a special reality documented in the personal home movie "portrait of life." Commonplace behavior, mundane activities, and everyday happenings do not get recorded. Just as we cannot easily see our own culture, we tend not to find it with our cameras.
When one considers all forms of filmic recording that in any way present, illustrate, or illuminate the human and socio-cultural condition, home movies are stereotypically thought to show the most accurate and realistic picture of everyday life. On a relative scale, this may be the case. However, if Martians or Venusians should study our home movies long after we have ceased to exist, they would, in fact, have a carefully constructed and biased view of everyday life. ${ }^{42}$ Without knowing how home movies function as a specific product of symbolic manipulation used within a specific process of visual communication within a cultural context, observers could not make valid inferences about the behavior shown on film. This is so for any form of visual representation from which we try to gain knowledge about the past, present, or future state of the human and social condition.

\section{NOTES}

1 A preliminary version of this paper was presented in the Sym-
posium on Ethnographies of Visual Communication at the 71st
Annual Meeting of the American Anthropological Association,
Toronto, 1972. The writing of this version was facilitated by a
Faculty Research Grant from Temple University, 1975. I wish to
thank Sol Worth and Jay Ruby for critically reviewing earlier drafts of
this paper.
20ther forms of native accounts have been studied such as
letters, diaries, notebooks, journals, dreams, and expressive interviews
(see Gottschalk, Kluckhohn, and Angell 1945; Webb, Campbell,
Schwartz, and Sechrest 1966). However, visual materials such as snap-
shots and family films have been neglected.
3 'The theoretical orientation used in this paper has been devel-
oped largely from the writing and research of Sol Worth and Dell
Hymes. For the development of Worth's vidistic perspective on film
and the subsequent emergence of "sociovidistics," see Chalfen (1974).
For a statement regarding the anthropological relevance of vidistic
fieldwork and the contextualization of film as a symbolic form, see
Worth (1972) and Worth and Adair (1972).
4 The notions of a communication "event" and "component"
have been borrowed from Hymes' ethnography of speaking paradigm
(1962, 1964, 1972). While Hymes dealt directly with verbal symbolic
forms, attention in this paper is to visual forms. Thus I am simulta-
neously examining the assumption that Hymes' theory of communica-
tion is general enough to be applied to a variety of communication
modes (see Hymes 1964 for an explicit statement of the change from
"speaking" to "communication").
5 The qualification of "home movie content" should be emphasized. As will be demonstrated later, this film might not be included in a home mode context because of its subsequent use in public contexts rather than private ones.

${ }^{6} \mathrm{No}$ attempt has been made to study sound home movies for this report.

${ }^{7}$ In this sense Nikons and Leicas can be used as well as Instamatics and Polaroids for the still counterpart of home movies, namely, family album snapshots.

${ }^{8}$ For the film critic, home movies have sometimes represented a standard for the evaluation and comparison with other more professional forms. For instance, Nicholas Pileggi's review of The Godfather is titled "The Making of 'the Godfather'-Sort of a Home Movie" (1971), and Joe Adcock's recent review of $A$ Woman Under the Influence is titled "John Cassavetes' Latest Is a Draggy Home Movie" (1975).

${ }^{9}$ Another example is Dawson Family Reunion. Harry Dawson, Jr., made a Super- 8 film of his family's reunion at the request of his father. Subsequently, Dawson entered the movie "on pure whimsey" in the annual Oregon Filmmakers Festival. The film won first place (personal communication 1974). 
${ }^{10}$ Another interesting example of the usurpation of home moviemaking is the Bar Mitzvah scene in The Apprenticeship of Duddy Kravitz (1974) directed by Ted Kotcheff.

${ }^{11}$ Films in this category include Ricky and Rocky by Jeff Kreines (Chalfen 1975a), Mother Marries a Man of Mellow Mien by Abigail Child, A Visit to Indiana by Curt McDowell, and Going Home by Adolphas Mekas and Pola Chapelle.

${ }^{12}$ The home movie efforts of the Kennedy family and movies of Hitler's home life have been shown on television during the past five years. Most recently, the home movies of Bob Haldeman appeared on a Mike Wallace CBS News Special, arousing further interest in Watergate activities and "back-stage" White House life (Dean 1975).

${ }^{13}$ Additionally, Professor George Semsel, in the College of Fine Arts at Ohio University (Athens), directs an "annual home movie festival at which the local community is invited to screen such films" (private communication 1973).

${ }^{14}$ This project was directed by Steve Zeitline, assisted by Amy Kotkin. Zeitline and Buddy Star produced a film titled Home MovieAn American Folk Art as part of this project (see Fisher 1975).

${ }^{15}$ The progression of research projects completed by Worth and his students is particularly interesting in this regard. Worth first observed the making of "bio-documentary" films (a form of nativegenerated film) by white middle-class graduate students (see Worth 1965). In collaboration with John Adair, Worth then observed a group of Navaho Indians make films about themselves for the first time (see Worth and Adair 1972). Subsequently, several of Worth's graduate students began to instruct and observe urban teenagers as they produced films in their own neighborhoods (see Achtenberg 1967; Chalfen and Haley 1971; and Chalfen 1972). And most recently, I have begun to investigate movies and still photographs made by white middle-class families as part of the home mode of visual communication (see Chalfen 1975b). However, the "primitive" or "naive" qualities of these different forms of visual communication do not singularly serve to unite all these forms under the heading of "home movies."

${ }^{16}$ It is surprising to find that home movies are not mentioned in appropriately titled references as The Use of Personal Documents in History, Anthropology and Sociology (Gottschalk, Kluckhohn, and Angell 1945), Visual Anthropology: Photography as a Research Method (Collier 1967), Unobtrusive Measures: Nonreactive Research in the Social Sciences (Webb, Campbell, Schwartz, and Sechrest 1966) just to mention a few.

${ }^{17}$ It is interesting to notice the terminology used in this short quotation. Three of the four film communication events (planning, filming, and editing) are mentioned. The neglect of exhibition activity is a common characteristic of the HTDI manuals.

${ }^{18}$ We may speculate that when people begin to plan their filmmaking (versus moviemaking) they are leaving the home mode and entering an "amateur mode." Readers should notice that this shift may have nothing to do with camera technology.

${ }^{19}$ For a set of instructions for how to pose for the family snapshot, see "Do Your Pictures Flatter You?" (Woman's Day, November 1971, p. 17) or "Camera Shy? Practice to Overcome It" by Mary Sue Miller (Evening Bulletin, January 16, 1973, p. 58).

${ }^{20} \mathrm{~A}$ consideration of editing is important to the transformation of home movie footage to an "artistic" mode. For instance, Clay Colt, writing on "Home Movies-Beyond Nostalgia and Kitsch," outlines three possible ways that filmmakers can use raw home movie footage:

rearranging existing old movie footage; editing one's own home movies with an end in mind that goes beyond being "just home movies;" or drawing on the naive style while enriching the content to develop a strong aesthetic or social statement [1974:6].

${ }^{21}$ For an account of editing still photographs in the production of a family album, see Jeanne Lamb O'Neill's article "All in the Family Album" (American Home, August 1972, p. 22).

${ }^{22}$ The importance of showing home movies was mentioned by Don Sutherland, a regular contributor to Popular Photography. $\mathrm{He}$ made a meaningful distinction between professional and amateur filmmakers:

As a pro, I enjoy the challenges of shooting movies; as an amateur, my pleasure is in showing them ... What makes it worthwhile is seeing the event replayed on the screen ... [1971:123].
${ }^{23}$ For a satiric account of an exhibition event in a related form of home mode visual communication-namely, travel slides-see Leonard S. Bernstein's "How to Stop Them-After They've Photographed Paris," House Beautiful (October 1972, pp. 171-172).

${ }^{24}$ For purposes of exposition and the avoidance of awkwardness, the term "actor" shall refer to both males and females, just as "cameraman" should be read as "cameraperson."

25 "Anyone" must be understood to include animals whether it be simply a household pet or a "star" such as Lassie, Rin Tin Tin, or Benji.

${ }^{26}$ Beach scenes may include a sleeping person-an inclusion determined by a change in setting.

${ }^{27}$ Casts on a child's broken arm or leg, covered with signatures, were seen several times, however.

${ }^{28}$ This has not always been the case for the message form "snapshot." At one time, the photographing of dead people in caskets for the photograph collection was commonplace. I have collected several exámples of this behavior from Polish and Italian families.

${ }^{29} \mathrm{~A}$ common attitude is that cameras take the pictures and that the people behind the cameras have very little to do with the process. In this sense, the cameraman becomes a bystander, while the competent technology of the camera apparatus is totally responsible. Camera advertisements clearly foster this attitude, presenting an image of the helpless picture-taker who needs the totally automatic, in some cases, computerized camera. For another approach, see Paul Byers' "Cameras Don't Take Pictures" (1966).

${ }^{30}$ Quoted from an advertisement for a GAF home movie outfit sold and distributed by the Gulf Oil Company to their credit card holders.

31 Jonas Mekas, avant-garde filmmaker and film critic for the Village Voice, praises the film Man of the House, made in 1924 by Carl Dreyer, for his attention to everyday things and activities:

the film is full of most precise and most beautiful details from the daily life at the beginning of the century. All the little things that people do at home, in their livingrooms, in their kitchens, you can almost smell and touch every smallest activity, detail. In a sense one could look at it as an ethnographic film [April 2, 1970]. This extreme attention to everyday detail may, in fact, belong to another film genre, either that of the "art" film or the "ethnographic" film.

${ }^{32}$ This distinction is important in some, but not all, genres of film communication. For instance, in a Hollywood production, the setting of the filming event may be a studio or a studio "lot," but the setting for the action of the film might be a western saloon, a livingroom, an airplane interior, and the like.

${ }^{33}$ However, some form of minor modification, such as cleaning a room, may precede filming.

${ }^{34}$ Rare exceptions occur in the case of a baby's bedroom, a young child's bath time, or a special dinner eaten in the kitchen.

35 "Special" is meant here in a positive sense. We do not find pictures of city slums, abandoned housing, or city dumps in home movies-at least not in home movies made of "our" society. However, these scenes may optionally be included in travel movies made of "other" societies.

${ }^{36}$ Moviemakers may feel awkward when their private images are shown in public places. One example is provided by Harry Dawson, Jr., who entered his home movie titled Dawson Family Reunion in the first annual Oregon Filmmakers Festival. The film was given "first place and sparked a very lively local controversy. I was chagrined; here's my private home movie up in front of everyone, some identify with it, others cry hoax! I was very upset... To me it's still mostly for family..." (personal communication 1974).

${ }^{37}$ Slight variation in the patterned choice of appropriate participants, settings and topics indicates a different genre of film communication. Some manuals urge readers "to organize home moviemaking into the spirited adventure it can be." We see some of the familiar components being used for different ends, changing the pattern of film communication. For example, one manual promoted the production and direction of home movies that will look like "downtown films":

Imagine shooting a no-guns Western in your own backyard starring 
your one and only Junior. A comedy that features Mother. A crime mystery, sports story, drama, legend or a community documentary that's meaningful at a town meeting... You have the cast and production crew: your own family friends and neighbors. All indoor and outdoor sets are home and hometown sites... Everything you need to know to organize home moviemaking into the spirited adventure it can be-a new kind of family and community participation! [Goodwin and Manilla 1971:viiviii].

Here we see that choice of on-camera participants and settings are appropriate, but choice of theme (comedy, mystery, legend, etc.) and exhibition participants (a town meeting) are not in the pattern of home movies.

${ }^{38}$ In most $8 \mathrm{~mm}$ cameras, the camera has to be stopped and the film spool turned over before the second 25 feet of film can be exposed. This is not necessary with the newer cartridge loaded cameras.

${ }^{39}$ Titles, credits, and "fin" are very infrequent. Home movies generally begin when there is film available to shoot and end when the supply of film runs out.

${ }^{40}$ We are not so concerned with what home moviemaking does to people in a strict effects orientation. More attention is paid to a functional approach which stresses what people do with the media (see Wright 1974).

${ }^{41}$ I am borrowing a lot from William Bascom's 1954 paper entitled "Four Functions of Folklore" in which he discusses "what folklore does for the people who tell and listen to it" (1954:342). Bascom stresses the notion of folklore maintaining the stability of culture: "Viewed thus, folklore operates within a society to insure conformity to the accepted cultural norms, and continuity from generation to generation through its role in education and the extent to which it mirrors culture" (1954:348-349).

${ }^{42}$ For a Venusian interpretation of a reel of film, see Arthur Clarke's "History Lesson" in Across a Sea of Stars (1959).

\section{REFERENCES CITED 1}

Achtenberg, Ben

1967 Making Not Much to Do: An Experiment in the Use of Documentary Filmmaking as a Tool in Communication Research. Unpublished MA thesis, Annenberg School of Communications, University of Pennsylvania.

Bascom, William

1954 Four Functions of Folklore. Journal of American Folklore 67:333-349.

Brakhage, Stan

1971 In Defense of the "Amateur" Filmmaker. Filmmakers Newsletter (Summer):20-25.

Byers, Paul

1966 Cameras Don't Take Pictures. Columbia University Forum $9(1): 27-31$.

Carpenter, Edmund

1972 Oh, What a Blow That Phantom Gave Me! New York: Holt, Rinehart and Winston.

Chalfen, Richard

1974 Film as Visual Communication: A Sociovidistic Study in Filmmaking. Unpublished Ph.D. dissertation, Annenberg School of Communications, University of Pennsylvania.

1975a Review. American Anthropologist 77:466-469.

1975b Introduction to the Home Mode of Visual Communication. Folklore Forum 13:19-25.

Chalfen, Richard, and Jay Haley

1971 Reaction to Socio-Documentary Filmmaking Research in a Mental Health Clinic. American Journal of Orthopsychiatry $41(1): 91-100$

Chalfen, Richard, and Sol Worth

1972 How Groups in Our Society Act When Taught to Use Movie Cameras. In Through Navaho Eyes, by Sol Worth and John Colt, Clay Adair. Bloomington: Indiana University Press.

1974 Home Movies-Beyond Nostalgia and Kitsch. University Film Study Center Newsletter 4(5):6-7.
Dean, John W., III

1975 Haldeman Is No More Innocent Than I Am. New York Times (April 6).

Feld, Steve, and Carroll Williams

1975 Toward a Researchable Film Language. Studies in the Anthropology of Visual Communication 2:25-32.

Fisher, Emily

1975 The Home-Movie Tradition: Everybody's Baby as Art. Washington Post (June 11).

Gottschalk, Louis, Clyde Kluckhohn, and Robert Angell

1945 The Use of Personal Documents in History, Anthropology and Sociology. Bulletin 53, Social Science Research Council, New York.

Hill, Richard, and Kathleen Crittenden, Eds.

1968 Proceedings of the 1968 Purdue Symposium on Ethnomethodology. Institute Monograph Series, No. 1.

Hymes, Del

1962 The Ethnography of Speaking. Anthropology and Human Behavior. Thomas Gladwin and William C. Sturtevant, Eds. Washington, DC: Anthropological Society of Washington.

1964 Introduction: Toward Ethnographies of Communication. The Ethnography of Communication. John Gumperz and Dell Hymes, Eds. American Anthropologist 66(2, pt. 2):1-34.

1972 Models of the Interaction of Language and Social Life. Directions in Sociolinguistics. John Gumperz and Dell Hymes, Eds. New York: Holt, Rinehart and Winston. pp. 35-71.

La Barre, Weston

1968 Comment on Hall. Current Anthropology 9(2-3):101-102.

Mead, Margaret, and Rhoda Metraux, Eds.

1953 The Study of Culture at a Distance. Chicago: University of Chicago Press.

Mekas, Jonas

1972 Movie Journal. New York: Collier Books.

Sussex, Elizabeth

1972 Grierson on Documentary: The Last Interview. Film Quarterly 26(1):24-30.

Van Gelder, Lawrence

1974 Film: Heroes, Ode to Home Movie. New York Times (December 15).

Webb, Eugene J., et al.

1966 Unobtrusive Measures: Nonreactive Research in the Social Sciences. Chicago: Rand McNally.

Worth, Sol

1965 Film Communication: A Study of the Reactions to Some Student Films. Screen Education Yearbook. London: Wm. Dresser and Sons. pp. 3-19.

1966 Film as a Non-Art: An Approach to the Study of Film. American Scholar 35:322-334.

1970 The Development of a Semiotic of Film. Semiotica 282-321.

1972 Toward an Anthropological Politics of Symbolic Forms. Reinventing Anthropology. Dell Hymes, Ed. New York: Vintage Books. pp. 335-364.

Worth, Sol, and John Adair

1972 Through Navaho Eyes-An Exploration in Film Communication and Anthropology. Bloomington: University of Indiana Press.

Wright, Charles

1974 Mass Communication-A Sociological Approach. 2nd edition. New York: Random House.

\section{REFERENCES CITED 2 HOME MOVIEMAKING MANUALS}

Bell and Howell

n.d. Now That You're in Show Business.

Duitz, Murry

1960 Better 8 mm Home Movie Guide. Modern Camera Guide Series. Philadelphia: Chilton.

Eastman Kodak Company

1966 How To Make Good Home Movies.

1968 Better Movies in Minutes. 
1970 Home Movies Made Easy.

1972 Editing Your Movies.

Gilman, Edwyn

1963 Photographer's Guide to Movie Making. New York: Amphoto.

Goodwin, Nancy, and James Manilla

1971 Make Your Own Professional Movies. New York: Collier Books.

Grosset, Philip

1963 Planning and Scripting Amateur Movies. London: Fountain Press.

Knight, Bob

1965 Making Home Movies. New York: Collier Books.

Matzkin, Myron A.

1964 Family Movie Fun for All. New York: American Photographic Book Publishing Co.

Schultz, Ed, and Dodi Schultz

1972 How To Make Exciting Home Movies and Stop Boring Your Friends and Relatives. Garden City, NJ: Doubleday.

\section{REFERENCES CITED 3 ADVICE COLUMNS}

Anon.

1968 How You Can Make Better Home Movies. Better Homes and Gardens (November):132-134.

Babcock, David

1971 It's Fun to Make Home Movies. Parents 46(January):50-52. Peter, John

1965 Livingroom "Spectaculars": Home Movies. Look $65($ March $): 50$.

Smith, Steven T.

1975 Editing Will Improve Every Home Movie. New York Times (June 22).

Sutherland, Don

1971 A Good Home Movie Is Not Necessarily "Well Made." Popular Photography (October).

n.d. Human Relations-How to Make Films Without Losing Friends. Travel and Camera.

\section{REFERENCES CITED 4 FILMOGRAPHY}

A Visit to Indiana. Directed and produced by Curt McDowell (n.d.). $16 \mathrm{~mm}$, color, optical sound, 10 minutes. Distributed by Canyon Cinema, Room 220, Industrial Center Building, Sausalito, CA 94965 .
Film Portrait. Directed by Jerome Hill (1971). $16 \mathrm{~mm}$, color, optical sound, 80 minutes. Distributed by Filmmakers Cooperative, 175 Lexington Ave., New York, NY.

Going Home. Directed and produced by Adlophas Mekas and Pola Chapelle (1972). $16 \mathrm{~mm}$, color, optical sound with English narrative, 61 minutes. Distributed by New Yorker Films, 43 West 61st St., New York, NY 10023.

Heroes. Directed by Frederick Becker (1974). $16 \mathrm{~mm}$, color and black and white, optical sound, 90 minutes. Distributed by Vision Quest, Inc., Box 206, Lawrenceville, NJ 08648.

Home Movie-An American Folk Art. Directed by Ernst Star (1975). $16 \mathrm{~mm}$, color, optical sound, 25 minutes. Distributed by the Division of the Performing Arts, Smithsonian Institution, Washington, DC.

Mother Marries a Man of Mellow Mien. Directed and produced by Abigail Child (n.d.). $16 \mathrm{~mm}$, color, optical sound, 8 minutes. Distributed by Abigail Child, 114 East 13th St., New York, NY 10003.

Ricky and Rocky. Directed and produced by Jeff Krienes and Tom Palazallo (1974). $16 \mathrm{~mm}$, color, optical sound, 15 minutes. Distributed by Vision Quest, Inc., Box 206, Lawrenceville, NJ 08648.

Six Filmmakers in Search of a Wedding. Produced by Pyramid Films (n.d.). $16 \mathrm{~mm}$, color, optical sound, 13 minutes. Distributed by National Educational Film Center, Finksburg, MD 21048.

The Apprenticeship of Duddy Kravitz. Directed by Ted Kotcheff (1974). Produced by John Kemeny, starring Richard Dreyfus, Micheline Lanctot and Jack Worden. Panavision and color, $35 \mathrm{~mm}$, 120 minutes. Distributed by Paramount Pictures.

Up the Sandbox. Directed by Irvin Kershner (1972). Produced by Irwin Winkler and Robert Chartoff. Released by First Artists. Starring Barbra Streisand and David Selby. Technicolor, $35 \mathrm{~mm}$, 100 minutes. Distributed by National General Pictures.

\section{FIGURE CREDITS}

Figure 1 - from the New York Times (4/6/75).

Figure 2 - from the Evening Bulletin (3/30/73).

Figure 3 - from Rewind (Vol. 14, No. 6, 1972), a publication of Deluxe General Inc.

Figure 4 - from the Evening Bulletin (11/25/72).

Figure 5 - from Today's Filmmaker (4/75, p. 48).

Figure 6 - from Popular Photography (10/71, p. 122).

Figure 7 - from the Evening Bulletin (4/6/73).

Figure 8-from The New Yorker. 